\title{
Writing Scripto-Visual Costumes and Columns of Air
}

\author{
Redell Olsen
}

It is a 'work', if it may be so called, named Frameworks. It is a lengthy, fragmented, and difficult set of speculations, arguments and assertions as to how a column of air could be identified and defended as a work of art or not. But a column of air could be described in many ways. You couldn't easily point to it. Immediately the problem of the 'metaphysical' location of the work of artwas encountered. Was it a column of air or was it a sort of fictional entity? Was it the argument, the 'theory' and speculation or the text? The object was being made by the text. Its independence as an art object was being eroded. Many of the dematerialised clichés of post-minimalism are present but the art object risks the condition of mere 'as if' insofar as the object - turns into text and the conventional powers of the artist are transformed into those of a participant in discursive talk. Mel Ramsden discussing Frameworks (1966-1967). (Art \& Language, Tate Papers, 2004).

In "The Trouble with Writing” Charles

Harrison describes the work of Art and Language with an avowed sense of suspicion for the literary:

Much of the work of Art \& Language is written. Some of this writing has been hung on walls or stuck on walls, some painted on walls, or printed on paintings, or stuck to paintings. Some of it has been published in books and catalogs and journals. But none of it wears the costume of literature. It is artists' writing. ${ }^{1}$

I wonder if Frameworks (Art \& Language, 1966-1967) with its famously "identified and defended" column of air is as unliterary as Harrison suggests? Much as I admire Harrison's critical writing, I can't help 
wondering if his ideas of the literary are somewhat lost in an idea of literature more relevant to the $19^{\text {th }}$ century novel. The phrase "costume of literature" is a troubling one that captures the long-standing distrust of art and artists for the literary even as the use of language has become, since the 1970s, relatively commonplace in the domain of artistic practice. The term "costume" carries with it the now rather rare if not obsolete sense of "costume" as linked to the style of an artwork in relation to the expectations of its historical and cultural context. On a basic level, Harrison's turn of phrase probably alludes to the modes of writing and language use more commonly found in literature than art of the time such as: narrative, description, and figurative language. This interpretation would soften his apparent disavowal of the literary into a simple acknowledgement of the different historical and social domains of these two artistic fields of research and practice. These prohibitions are less adhered to in recent work, but the suspicion between disciplines remains. The term "costume" also carries with it the weight of a long history of intellectual snobbery
Costume and fashion have a long history of being derided by serious intellectuals:

"Nothing else is
garish apparraile,
but Prydes ulcer
broken forth."
- Thomas Nashe,
The Anatomie of
Absurditie (1589)
"Fashion is the
abortive issue of
vain ostentation and
exclusive egotism:
it is haughty,
trifling, affected,
servile, despotic,
mean and ambitious,
precise and
fantastical, all in
a breath - tied to
no rule, and bound
to conform to every
whim of the minute."
- William Hazlitt,
On Fashion (1818)


and criticism in this mode usually reveals a bias against fashion as an art form alongside the consumer of fashion who is often a woman. Of course, Harrison's focus is not fashion or gender, and this imposed diversion into costume raises a set of concerns that are not the focus of Art \& Language.

Nevertheless, it is a significant phrase as it captures some of the difficulties that I want to dress here in relation to conceptual art and writing. In the same essay, Harrison describes three (and only three) categories of writing available to artists: "writing conceived as documentary accompaniment to artistic practice, writing conceived as literature, and writing conceived as art."2 It is the last of these possibilities that he is principally concerned with. There is, of course, no mention of poetics or a writing that
ALAMODE : thick silk (1692)

APYKED : embroidered (Chaucer)

ARMAZINE : strong corded silk (16 $6^{\text {th }}$ century)

CHEMISETTE : lace frill to fill neckline (1505)

FOREPART : stomacher

FRISETTE : band of artificial curls on forehead

INCARNADINE SATIN :

crimson in shadows, pink in highlights

( $16^{\text {th }}$ century)

LAPPEMANTLE : apron

MARRY-MUFFE : coarse cloth

PURFLE : embroidered edge of garments

RASH : inferior stuff

WEEPER : mourning hat band or widow's white cap

ZONE : girdle

- OED

\section{This column of AIR FLICKERS with very different cOSTUMES of art forms}

begin to look away from seeing and reading the dematerialised artwork; there emerges a new possibility, a poetics of flickers that crosses through the categories and hierarchies imposed by others or 
blurs the distinction between any number of these categories. It is worth asking whether certain strains of conceptualism depend on the assumption of such categories in order to maintain the assertion that writing could be a replacement for the messy complexities of painting? If language is approached as a painter might approach the possibilities of paint, then such categories would soon dissolve.

Harrison's description of this suspicion of literary costume is published over thirty years after Frameworks was conceived, and so cannot be said to be part of the initial "costume" of expectations surrounding the first wave of conceptual art at the end of the 1960 and early 1970s. It is written from a position of reflection, one that is nearly ten years after what many feminist critics, such as Nina Felshin, writing in the mid-199os, identified as a continuation of the work of the feminist artists from the $1970 \mathrm{~s}$ to recognise and incorporate "traditionally feminine materials" such as fabric, sewing and
In "The Response As Such: Words in Visibility" (1991), Charles Bernstein criticises contemporary artists for their bland use of text and accuses many visual artists of "seem[ing to be] hostile or ignorant of the literary or poetic traditions that are relevant to their language use." ${ }^{3}$

of Course, This One is For You Language and Art

Arrive at the place on the WHITE CARD with walls at least the writing seems insured.

This column is hair

writhing reads itself

THIS WAY

time can be said

and I am saying it

as 
clothing as "viable subject matter and formal means for art." ${ }^{4}$ In her article Felshin draws attention to the then "recent tendency among contemporary [female] artists to represent clothing as abstracted from the human body...." ${ }^{5}$ These artists were pursuing the possibilities of costume not as extraneous and ornamental but as both form and content of their work. In the same issue of $A r t$ Journal Emily Apter highlights the long line of feminist critics: Joan Riviere, Lucy Irigaray, Michele Montrelay, Mary Ann Doane, Judith Butler, Joan Copjec who have taken up the possibilities of costume and masquerade as an important philosophical and conceptual space through which to consider the constructed nature of the feminine.

A previous generation of Feminist artists of the 1970s had already incorporated the discourse of philosophy into their practice and moved towards an often unstable and flickering

\section{AM NOT OUT OF THE WORDS YET}

\author{
Worried enough \\ about being \\ a mere costume \\ of letters, \\ I forgot you \\ were wearing \\ a dress \\ or is that Art \\ \& Language \\ My writing \\ smock? \\ Overheard, \\ really, so \\ they hate \\ that literary \\ stuff.
}

\section{WHAT FANNY}

I, a-pool-of-cheese 
surface of scripto-visual

possibility. This term was used by the artist Mary Kelly in the 1970 s to describe an emerging hybrid practice that combined writing, image making, and the incorporation of objects, including clothes, into her work. Her Post Partum Document (1973-1978), an installation which traces the development of the mother/son relationship from birth until the infant's acquisition of speech, exemplifies the practice of the scripto-visual as one that refuses the boundaries of existing disciplines. The text is comprised of a variety of textual materials, including soiled nappies, feeding charts, stains, folded vests, diagrams, a mother's diary entries, and her son's first attempts at mark-making. Through Post Partum Document Kelly engages with the personal, social, and artistic constraints which shaped her as both a mother and as an artist. It is these constraints which shape the process of her investigation into discourses as diverse as drawing, science, autobiography, and theory towards a new literary and artistic possibility for the consideration of the necessary costume of the age. funny

sort of

\section{AS I SUSPECT}

he quotes

Horace and

expects people

to come

back smiling

with Ut Pictura Poesis

\section{is Her Name}

EVEN

which it rarely

is but could be

FAIRLY RADICAL 
As Lucy Lippard points out, Kelly's hybridity in this early work entails the disruption of customary feminist biological/

autobiographical approaches that are usually associated with archetypal representations of the mother and child. ${ }^{6}$ Instead, the text poses the problem of how to represent what has been omitted from the traditional discourses of motherhood. Kelly overturns the stereotypical representation of the mother as cultural object by producing a scripto-visual record of process. Her work asserts that the type of subjectivity explored by the scripto-visual is multilayered and various as it emerges from the points at which stain, mark, word, image, and utterance overlap in an articulation of the difference between the "unified transcendental subject of autobiography" and the "decentered, socially constituted subject of mutual discourse."7

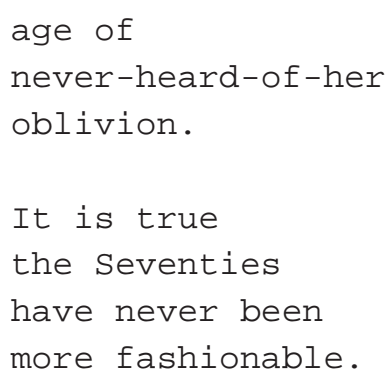

\section{LOOKCRAFTY}


Kelly further genders this gap; she claims that the scriptovisual allows her to "show the difficulty of the symbolic order for women" to stress how the production of the subject "is primarily a question of positionality in language." In a piece from Kelly's Documentation I (the first part of Post-Partum Document's six installations) several pairs of stained nappies are displayed with a timetable of foods ingested by the baby. The type-written words about eating are faint to the point of being like a nearly illegible stain.

my disciplinary

norms aren't

faking it terribly convincing as nothing doing

so much black ink or afterall

that only

the imprint no medium

specific recursive

structures here.

All Flies on YOKO.

Well, except that

I'm feeling this

deep inside

from my language

\section{LOOKNOLYRE}

perspective. Stop

CUT your quota

of a Xerox scanned 
defdemtao of feeding. Neither text is legible in the contuentional sense, but both can be read or seen as a type of writing in revolt at conventional forms. A child's costume is offered as an invitation to consider other possibilities at the selvedge of meaning where lines might and do cross.

no harm done

in the web

of ghostly

tradition

was all I had as

proof.

You mean that

existentially

I presume?

Someone says

looking for

an argument,

'Not especially,'

I say, like

it might be

time to go

home as the uncanny

This was before

I noticed that Joan Riviere, author of

'Womanliness as Masquerade' 
was a court dressmaker before she became a writer and psychoanalyst.

Schor emerged onto the West Coast arts scene during the 1970's. Schor's parents were Jewish immigrants from Poland, and Schor links her family history to her interest in language, pointing out that "[t]he child of an immigrant is traditionally the family interpreter."10 How this role of "interpreter" manifests itself in relation to art's practice is an important characteristic of Schor's work, who reinterprets her own personal relationship to language through an exploration of its visual forms. Interpreting her work becomes as much about seeing as about reading: "The writing as image was as much a metaphor of language-based thought as it was text to be read."11 Schor's "Dress Book" (1977), consists of body size translucent layers of rice-paper which were covered in writing. According to Schor the "elegant indecipherability" of her handwriting could be read as "an image and metaphor of female thought."12 At first glance, this assertion raises problems suggesting, as it does, an equation of the murky, the opaque with writing by women. If, however, we consider Schor's assertion in the light of the practice itself, it becomes evident that what she is actually stressing the whole field

was speculative

as gold was once now all

out in the bins

on the hunt

for the lost

bite at

the ephemera

cherry

to make

sense of our

burst

shelves.

Its all about talk now.

You said.

You and me,

talking it

up, you know

this one

is for

you

let's participate

a little 
is the relationship between the scripto-visual elements of the work-i.e. the marks and handwriting on the translucent paper, elements that, in terms of signification, place the work in a territory that must be negotiated by both "reading" and "seeing," practices which are usually reserved for apparently distinct disciplines. Important to Schor was the interaction between this piece and the viewer: "[Y]ou could go up to the 'woman' / artwork, turn its pages, trying to read her text (which was personal and autobiographical)."15 The reader/ viewer is asked to respond both to the work's physical and material characteristics as well as to its semantic properties.

Schor's work also has

affinities with the hybrid practice of the late Nancy Spero. Spero's 1967 works of gouache on paper, "Love to Hanoi" and "Bomb and Victims to Individual Shelters" take on forms that are reminiscent of both bomb clouds and full-length dresses. From 1969 Spero's work combined image and text in painting and type-writer collages, which extend on long scrolls of paper, and she produced
In an essay on the filmmaker Chris Marker, the poet Susan Howe describes the close similarities between her practice as a poet and that of the filmmaker who uses "split sequences, 'disruptiveassociative montage'" and places "emphasis on the mysterious patternment and subliminal structures of images (icons)."13 For Howe Marker's film Sans Soleil is about editing and quotation. ${ }^{14}$ Howe recognises her working methods in the practice of Marker, who she describes as recording the "sensitivity to the sound shape (even in silent film) of each pictured event" and shows an "awareness of the time-mystery of simultaneous phenomena (co-occurrence and deployment)."16

Benjamin Buchloch reads Spero's "duality of painting as writing and of writing as painting" in ways that are relevant for the consideration of Howe's own work. He describes how Spero's methods are crucial 
scripto-visual installations that have been screen-printed directly onto the gallery wall. The scripto-visual is for Spero a way of representing the effect of pain on language. Pain which not only resists language but destroys it. In "The Codex Artaud," the illegible "stutter" of visual marks and traces becomes a vehicle for expressing the corporeal pain of the incarcerated writer. This relationship between the scripto-visual and an investigation of the corporeal body is also evident in Spero's "Notes in Time" (1976-1979) series, which collages together witness accounts gathered by Amnesty International of torture, brutality, and missing persons in the dictatorships of Chile, Argentina, and El Salvador. In this sequence, Spero uses a mix of handprint and typewriter collage. The illegibility of words and phrases that have been wiped out, printed over, and smudged into one another, seems to suggest an attempt to document the lives of the disappeared through a practice which foregrounds the material effacement of letters and phrases. for a redefinition of the hierarchies and boundaries of discourses between the visual and the verbal:
Not only are the literary
dimensions of culture invoked in a gesture that mourns the hermetic inaccessibility of those cultura legacies, but the literary dimension is also reinscribed as an aggressive challenge to the myopic definitions of the pictorial in the modernist framework and of the linguistic in conceptual art. ${ }^{17}$

The scripto-visual is not only a visual category; it is also a mode of writing. 
Not the poem as idea as idea but ideas in words as words. Not that the poem does not think that words are not made of materials. Not the dematerialisation of the poem but the intermittent re-materialisation of the word as object. Not an assumption of language as transparent but an exploration of its densities. Not that what is the matter with poetry matters to art much anyway. Not that it sells anything. Not that the poem can even call itself a work. Not that it wants to work even. Not that poetry is not thinking matter. Not that poetry is not a matter of thinking. Not that the idea or concept is the most important aspect of the poem. Not that poems are without materials called words, called concepts sometimes. Not
I'll Drown My Book: Conceptual Writing by Women (2011) was conceived by its editors as a riposte and an extension to the remit of the Anthology Against Expression (2011). For many writers, particularly female writers, this anthologywhile widely taken up in the very contexts of possible overlap between visual arts practice and poetics- seemed to miss some of the scriptovisual connections and conversations between philosophy, poetics, feminism, and art that had been underway for some time across the poetry and the visual arts. The editors of I'll Drown My Book brought together writing by female writers working out of and alongside the conceptual approaches to writing made possible by modernism, Conceptual Art, Language Writing, and a previous generation's feminist articulation of a scriptovisual practice across many different media. 
that poems are without these. Not that these do not call into question concepts and make them happen, or not. Not that conceptual is the only way of calling thinking in art that. Not that the poem does not think for itself already before it gets called one. Not that it does not already consider language as a conceptual figure. Not that the poem is not aware of traditional verse forms. Not that it does not know how to be one of them. Not that it is not one ever. Not that this is anything new in poetry and not necessarily conceptual in the least. Not that all of the planning and decisions need to be made beforehand. Not that whose hand is writing is not mattering. Not that this poem could not be found already existing elsewhere as a roadside sign. Not that poetry can proceed further without
In her introduction Laynie Browne points out the limitations of the prevalent use of the term conceptual writing:

"The fact is, that the term 'conceptual writing,' for better and for worse, has thus far often been employed to describe a set of writing practices which seem, nonsensically, to preclude particular content."18

The section headings of I'll Drown My Book (process, structure, event, matter) reveal as a differing attitude to form from Goldsmith and Dworkin's anthology. The writing in I'll Drown My Book approaches language not as a transparent medium but as a material site of discovery, out of which ideas can be shaped. The investigations and explorations of the material properties of language-which often 
an exploration into the materials necessary. Not that the execution of the poem is a perfunctory affair that does not care if it is one. Not that the form becomes a machine that makes the poem by forgetting what it was made of. Not that it is not natural. Not that the poem does not question nature. includes overlaps with mark and image makingare foregrounded in relation to its social and contextual tensions and associations of words. Not that art is anxious about what poetry thinks. Not that art is always thinking. Not that art thinks much about what poetry is thinking.

Not that the poem could be anything more than itself.

Not that the poem knows what is understood as poetry but is questionable as that. Not that the poem knows everything including what it might be. Not that the poem could be just that. Not that the poem could be one necessitates it being one. Not that the literary is anxious about what art thinks. Not that writing is always thinking. Not that the writing could be anything more than two columns of air flickering with a poetics of the scripto-visual, some half-glimpsed possibilities, costumes still to be cut writing across boundary seams. 


\section{Endnotes}

1 Charles Harrison, "The Trouble with Writing," in: Conceptual Art and Painting: Further Essays on Art \& Language. Cambridge, MA, London: MIT Press, 2001, pp. 3-34: here p. 3.

2 Ibid.

3 Charles Bernstein, "The Response as Such: Words in Visibility," in: $M / E / A / N / I /$ $N / G 9$ (1991), pp. 3-8: here: p. 6.

$4 \quad$ Nina Felshin et al., "Women's Work: A Lineage, 1966-1994," in: Art Journal, 54:1 (1995), pp. 71-85: here p. 71.

5 Ibid.

6 Lucy Lippard, "Foreword," in: Mary Kelly, Post-Partum Document. Berkeley, CA: University of California Press, 1999 [1983], pp. xi-xvi: here p. xiv.

7 Mary Kelly, Imaging Desire. Cambridge, MA: MIT Press, 1996, p. 23.

8 Ibid.

9 Mira Schor, “Women's Work: A Lineage, 1966-1994." Art Journal 54:1 (1995), p. 76.

10 Mira Schor, Wet: On Painting, Feminism, and Art Culture. Durham, NC: Duke University Press, 1997, p. 210.

11 Schor (1997), Wet, p. 211.

12 Schor (1997), Wet, p. 210.

13 Susan Howe, "Sorting Facts; or, Nineteen Ways of Looking at Marker," in: Charles Warren, ed., Beyond Document: Essays on Nonfiction Film. Hanover, CT: Wesleyan University Press, 1996, pp. 295-343: here p. 300.

14 Cf. Lynn Keller, "An Interview with Susan Howe," in: Contemporary Literature 36:1 (1995), pp. 1-34: here p. 27.

15 Schor (1997), Wet, p. 210.

16 Howe (1996), Sorting Facts, p. 300.

17 Benjamin H. D. Buchloh, "Spero's Other Traditions," in: Catherine de Zegher, ed., Inside the Visible: An Elliptical Traverse of $20^{\text {th }}$ Century Art. Cambridge, MA: MIT Press, 1995, pp. 239-244: here p. 243.

18 Laynie Browne, "A Conceptual Assemblage. An Introduction," in: Laynie Browne et al., eds., I'll Drown My Book: Conceptual Writing by Women. Los Angeles, CA: Les Figues Press, 2011, pp. 14-17: here p. 15.

\section{Bibliography}

Apter, Emily, "Out of the Closet: Mary Kelly's Corpus (1984-1985)," in: Art Journal 54:1 (1995), pp. 66-70.

Art \& Language (Mel Ramsden, Charles Harrison, Michael Baldwin), "On Painting," in: Tate Papers 1 (2004), http://www.tate.org.uk/research/publications/tate-papers/o1/ on-painting, date of access: 17 Sept. 2018.

Bernstein, Charles, "The Response as Such: Words in Visibility," in: $M / E / A / N / I / N / G 9$ (1991), pp. 3-8. 
Browne, Laynie, "A Conceptual Assemblage. An Introduction," in: Laynie Browne et al., eds., I'll Drown My Book: Conceptual Writing by Women. Los Angeles, CA: Les Figues Press, 2011, pp. 14-17.

Buchloh, Benjamin H. D., "Spero's Other Traditions," in: Catherine de Zegher, ed., Inside the Visible: An Elliptical Traverse of 2oth Century Art. Cambridge, MA: MIT Press, 1995, pp. 239-244.

Felshin, Nina, et al., “Women's Work: A Lineage, 1966-1994," in: Art Journal, 54:1 (1995), pp. $71-85$.

Goldsmith, Kenny/Craig Dworkin, Against Expression: An Anthology of Conceptual Writing. Evanston, IL: Northwestern University Press, 2011.

Harrison, Charles, "The Trouble with Writing," in: Conceptual Art and Painting: Further Essays on Art \& Language. Cambridge, MA, London: MIT Press, 2001, pp. 3-34.

Howe, Susan, "Sorting Facts; or, Nineteen Ways of Looking at Marker," in: Charles Warren, ed., Beyond Document: Essays on Nonfiction Film. Hanover, ст: Wesleyan University Press, 1996, pp. 295-343.

Keller, Lynn, "An Interview with Susan Howe," in: Contemporary Literature 36:1 (1995), pp. 1-34.

Kelly, Mary, Imaging Desire. Cambridge, MA: MIT Press, 1996.

Kelly, Mary, Post-Partum Document. Berkeley, CA: University of California Press, 1999 [1983].

Lippard, Lucy, "Foreword," in: Mary Kelly, Post-Partum Document. Berkeley, CA: University of California Press, 1999 [1983], pp. xi-xvi.

Olsen, Redell, 'This One is For You' and 'Not, A Conceptual Poetics' are quoted in this essay. 'Not, A Conceptual Poetics' was first published in I'll Drown My Book: Conceptual Writing by Women. Los Angeles, CA: Les Figues Press, 2011.

Schor, Mira, “Women's Work: A Lineage, 1966-1994," in: Art Journal 54:1 (1995), p. 76.

Schor, Mira, Wet: On Painting, Feminism, and Art Culture. Durham, NC: Duke University Press, 1997 . 